\title{
Evolutionary Game and Steady State Analysis of Government and Real Estate Developers in the Development of Smart Community
}

\author{
Baolong Yang ${ }^{1, a}$ and Zuoliang Lv ${ }^{2,} b^{*}$ \\ ${ }^{1}$ School of economics and management, Dalian University, Dalian 116622, China \\ ${ }^{2}$ School of economics and management, Dalian University, Dalian 116622 , China \\ ayangbaolong2015@163.com, bgtqyzx@163.net,
}

\begin{abstract}
Keywords: Smart community; Evolutionary game; Replicator dynamics; Steady-state equilibrium strategy
\end{abstract}

\begin{abstract}
Government and real estate developers as the main responsibility for the development of smart community, this article selected the two stakeholders to study the evolutionary game of the smart community development decision-making, building a non- Symmetric $2 \times 2$ evolutionary game models and the dynamic evolutionary adjustment process is used to analyze the evolutionary stability strategy and its parameter condition of the game. The results show that the effective incentive mechanism of the government has promoted the positive effect of the reform and innovation of the real estate developers, which has promoted the government to further improve the incentive policy of the smart community construction. The steady equilibrium strategy of the government is the policy to encourage developers to transform innovation, real estate developers for the pursuit of maximum profits and innovation, which in theory confirmed the government incentive policy on the importance of the development of the smart community.
\end{abstract}

\section{Introduction}

To get rid of the dilemma of the current real estate market downturn and seek the future direction of the real estate industry transformation, and seek new connectivity of the Internet industry and the traditional real estate industry, promote the transformation of China's real estate industry innovation, construction with the smart integration of information technology application community projects become the strategic choice for many large developers. Intelligence community construction as its government community management and real estate developer transformation innovation, the important measures for implementing informatization leading and integration development strategy, establish the intelligence community status as a factor of wisdom city innovation and development. The implementation of the Internet and the development of the economic and social integration "Internet +" strategy, expand the network economic space, release the information productive forces, the intelligence community has become an important driving force driving the development of intelligent city. In promoting the intelligence community in the process of development and construction, the government as policy makers, heavily will dominate the intelligence community development direction, developers as implementers of the construction of the project, will determine the smart community projects can fall to the ground. Government and developers has become a strategic interaction main body, the two are in the strategic behavior of study each other after make the best decisions reaction, because of information asymmetry and bounded rationality under the condition of short-term behavior, its strategy behavioral response is a dynamic process, the adaptation of which showed the characteristics of the behavioral ecology [1].This article is mainly based on evolutionary game method, government departments and the real estate developer, intelligence community development as an important responsibility the main body, the article selected the two stakeholders, the evolutionary game, the two sides in the intelligence community development decision-making to the government of the wisdom of community development and 
real estate developers to build an asymmetric evolutionary game model of the $2 \times 2$, and copy the adjustment process to analyze the dynamic evolution the evolutionary stable strategy and its parameters of the game [2]. The mathematical model is constructed to verify the interaction between government and developer government incentive policies to promote the smart effectiveness of community construction, and discusses the two groups from the perspective of dynamic evolutionary stable strategy, provide certain reference for intelligent community development decision.

\section{Basic assumptions and models}

In order to build the model and simplify the need for calculation, the following assumptions are made:

Game side: Suppose the game side is bounded rational, and divided into two categories, namely the government and developers. Behavioral strategy: For the government, its strategy can be to encourage real estate developers to develop the smart community can also be discouraged, so its strategy to select the space (encourage, discourage); and for real estate developers, it also has two Choose, develop traditional residential quarters and develop intelligent communities, the strategy of choice for the space (traditional communities, smart community). Behavior strategy to take the proportion: Assuming that in the early stages of the game, the government chose to encourage developers to develop the smart community probability $\mathrm{X}$, choose the incentive to the probability of $1-\mathrm{X}$; real estate developers choose to develop the smart community ratio $\mathrm{Y}$, choose to develop a traditional community ratio of $1-\mathrm{Y}$.

Pay off matrix: The matrix of the two sides in the random game is shown in Table 1.

Table 1. The matrix of the two sides in the random game

\begin{tabular}{|c|c|c|c|c|}
\hline \multirow{4}{*}{ Government } & \multicolumn{3}{|c|}{} & \multicolumn{2}{c|}{$\begin{array}{c}\text { Developer } \\
\text { community } \\
\text { comand }\end{array}$} & $\begin{array}{c}\text { Smart } \\
\text { community }\end{array}$ \\
\cline { 2 - 5 } & & Probability & $\mathrm{Y}$ & $1-\mathrm{Y}$ \\
\cline { 2 - 5 } & encourage & $\mathrm{X}$ & $\mathrm{U}-\mathrm{M}+\mathrm{e}, \mathrm{V}+\mathrm{M}$ & $\mathrm{U}-\mathrm{M}, \mathrm{V}+\mathrm{M}$ \\
\cline { 2 - 5 } & discourage & $1-\mathrm{X}$ & $\mathrm{U}, \mathrm{V}-\mathrm{N}$ & $\mathrm{U}, \mathrm{V}$ \\
\hline
\end{tabular}

\section{Evolutionary game analysis of the government and the developers}

According to the above assumptions and gains matrix, when the government to encourage developers to build intelligence community expected revenue as follows:

$$
\left.U_{G 1}=Y(U-M+e)+(1-Y)\right)(U-M)
$$

When the government doesn't encourage construction intelligence community's expected return as follows:

$$
U_{G 2}=Y U+(1-Y) U
$$

So, the average expected revenue for the government:

$$
\bar{U}_{G}=X U_{G 1}+(1-X) U_{G 2}
$$

Similarly, when developers build intelligence community's expected return as follows:

$$
U_{E 1}=X(V-M+f)+(1-X)(V-M)
$$

When developers build traditional community of expected return as follows: 


$$
U_{E 2}=X(V+M)+(1-X) V
$$

So, the average expected revenue for the whole cluster developers:

$$
\bar{U}=Y U_{E 1}+(1-Y) U_{E 2}
$$

To introduce evolutionary stable equilibrium in the replication dynamic equation [3]: $\frac{d_{x}}{d_{t}}=X\left(U_{S}-\bar{U}\right)$, Replication dynamic is essentially describes a specific strategies adopted in one population proportion or frequency of dynamic differential equations of: $\mathrm{X}$ for a populations in proportion to the adopted strategy $\mathrm{S}$ game; Us to adopt the strategy "s expecting profit of the game party; $\bar{U}$ is $\mathrm{U}$ in the game using the strategy the average for all policies in the space; In proportion to the adopting strategy $\frac{d_{x}}{d_{t}}$ is the game the rate of change over time. The dynamic differential equation and describe the characteristics of the individual frequency changes in biological evolution of the natural selection process consistent with the replication dynamic process, so called "copy" dynamic equation [4]. So according to the replicated dynamic equation, after a simple operation to get the government adopts to encourage developers to develop intelligence community replicated dynamic equation is:

$$
\frac{d_{x}}{d_{t}}=X\left(U_{E 1}-\bar{U}_{E}\right)=X(1-X)(e Y-M)
$$

By the same token, the developer can be concluded that the cluster using intelligence community strategy replicated dynamic equation is:

$$
\left.\frac{d_{y}}{d_{t}}=Y\left(U_{G 1}-\overline{U_{G}}\right)(1-Y)[(f+N) X-N)\right]
$$

By (7), (8) constitute a system of differential equations to find the equilibrium of the system for the $(X, Y):(0,0),(0,1),(1,0),(1,1)$ and $(\mathrm{N} /(\mathrm{f}+\mathrm{N}), \mathrm{M} / \mathrm{e})$.According to Milton Friedman's algorithm, group dynamic differential equations constitutes a dynamic system, the stability of the equilibrium analysis can through the analysis of the Jacobi matrix of the system of local stability, the system of differential equations (7), (8), in turn, with respect to X, Y of the partial derivative, can be concluded that Jacobi matrix of the:

$$
J=\left[\begin{array}{cc}
(1-2 X)(e Y-M) & X(1-Y) e \\
Y(1-Y)(f+N) & (1-2 Y)[(f+N) X-N]
\end{array}\right]
$$

\begin{tabular}{|c|c|c|c|c|}
\hline & Equilibrium & Determinant and symbol & $\begin{array}{c}\text { Trace and } \\
\text { symbol }\end{array}$ & $\begin{array}{l}\text { Local } \\
\text { stability }\end{array}$ \\
\hline $\mathrm{O}$ & $X=0, Y=0$ & $\mathrm{MN}$ & $-(\mathrm{M}+\mathrm{N})$ & ESS \\
\hline A & $X=0, Y=1$ & $(\mathrm{e}-\mathrm{M}) \mathrm{M}$ & e $\quad+$ & instability \\
\hline B & $\mathrm{X}=1, \mathrm{Y}=0$ & Mf & $\mathrm{M}+\mathrm{f} \quad+$ & instability \\
\hline C & $X=1, Y=1$ & $(e-M) f$ & $M-(e+f)$ & ESS \\
\hline $\mathrm{D}$ & $\begin{array}{c}\mathrm{X}=\mathrm{N} /(\mathrm{f}+\mathrm{N}), \\
\mathrm{Y}=\mathrm{M} / \mathrm{e}\end{array}$ & $-(e-M) M N f] /[(f+N) e] \quad-$ & 0 & saddle point \\
\hline
\end{tabular}

Calculated the Jacobi matrix determinant in these five equilibrium values and symbols, and mark the value of the Jacobi matrix and symbols, and thus determine the five local stability of the equilibrium. Calculation results are shown in Table 2.

Table 2. Local stability analysis of dynamic system 


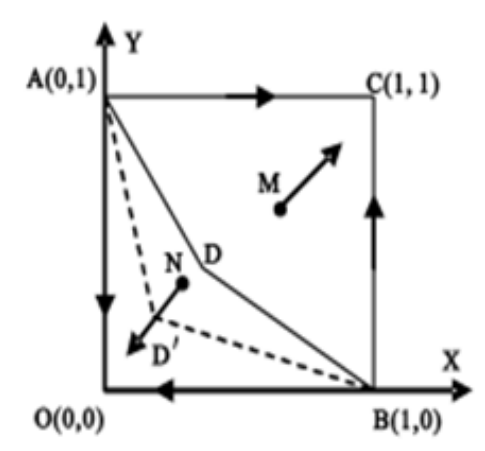

Figure 1. phase diagram in replicate dynamics system

\section{Parametric analysis of the model}

Analysis of parameters affecting initial state change by Fig. 1:

$\mathrm{e}, \mathrm{f}$ is respectively from the government and developers of real estate developer transformation development decision-making in the intelligence community's "super profits" in the distribution of income, as e increase D moves down, can be seen from figure 1 area OADB area CADB area increase, with the decrease of the area of system evolution to the possibility of ESS stable point $C$ increases. Similarly, when $\mathrm{f}$ increases, D moves to the left, the area of the regional OADB decreases and the area of region CADB increases, and the probability of system evolution to ESS stable point $\mathrm{C}$ is greater. From the above analysis can: both the government and developers, the greater the gains from development intelligence community behavior, the government is encouraging the greater the chance of developers to develop intelligence community, and developers to transform the greater the power of innovation, to form the government, developers, a win-win situation. From developers to build intelligence community behavior in order to be able to allocate to maximize returns, the government needs to provide a complete set of intelligent community development security system, mainly including land preferential system, market tax system, intelligent community development for developers to build a favorable external environment, to ensure that developers can be obtained from the transformation of innovation of the largest "super profits".

$M$ refers to the government to encourage developers to support the transformation of innovation to make a policy, such as research and development costs for some of the early high intelligence community management system and operating data of the late safety link, in order to encourage developers, director of the play and give the developer the government to support funds, such as tax refund policy, the equivalent of earnings in a redistribution between the government and developers. As $m$ increases, the more developers to obtain funding, in turn reduced the developer research and design of internal risk, the greater the likelihood of developers choose the development intelligence community, the government and developers from the transformation of income increase, namely, e and $f$ value increase, thus saddle point $D$, move to the left under the system evolution and the greater the chance of ESS stable point $\mathrm{C}$. $\mathrm{N}$ the developers choose the development community wisdom, but because the government does not encourage to promote community practice wisdom, does not provide a good market environment and the system of supervision market healthy development of the intelligence community, lead to speculative bubble, real estate developers suffer losses. When $\mathrm{N}$ increases, the saddle points move to the left, which means that developers are less likely to develop smart communities. This is in line with the actual situation, and the larger the initial losses of real estate developers, the more likely it is to choose the conservative strategy to invest in the construction of traditional residential communities [5]. Therefore, in the game when the initial choice of government incentive strategy, through the policy and market promotion, will naturally choose a great strategy, with the progress of time, the option incentive innovation transformation probability 
will be more and more big, the developers under the excitation government policy in pursuit of profits, choose to develop intelligent community, so the game into CADB area, game evolutionary equilibrium convergence of $\mathrm{C}$.

In real estate industry under the background of "the silver age", the government and the dynamical evolution of real estate developers should be carried out step by step in a long time, the main two game of strategy choice depends on the initial state of the two groups for their strategy choice proportion [6], and the proportion is decided by different to the strategy game participants benefits size. Government as the leading driving force of the smart community development, first of all must actively for real estate developers to create a good en vironment for the transformation of innovation, to carry out the relevant supervision work, to participate in the intelligence community is increased by the development of related businesses incentives, to strengthen the guide of traditional real estate residential developer service [7], provide smart community support to reduce the transition cost, dynamic adjustment measure such as intelligent community evaluation standard for the developers to build management cost reduction and revenue growth prospects, to real estate developers to promote the development of intelligent community management operations.

\section{Conclusion and prospect}

This paper confirms the importance of government incentive policy to the real estate developer's transformation and innovation, and divides the government's incentive policy into environmental protection policy and fund support policy, and discusses the two policies to encourage real estate development Business in the development of intelligent communities or traditional communities in the different roles. As the transformation of innovation has the externalities of revenue and the internal nature of the cost, resulting in the inherent lack of innovation power, and the government of these two policies to improve the innovation of externalities and internalities of the shortcomings, thus promoting the real estate developers to develop the smart community power [8]. At the same time developers to transform the positive effects of innovation, such as the entire real estate industry to promote the choice of technological innovation to gradually get rid of the industry trough, increasing the welfare of the community, etc., will prompt the government to further improve the wisdom of community development support policies. As a government side, the development of the smart community can not only strengthen the grass-roots construction and innovation of community governance; as a real estate developer, the benefits are mainly in the future for a long period of time to save operating costs, and improve the housing use Comfort, more attractive is the smart community's commercial operation, get rid of the drawbacks of traditional property management. It should be noted that this paper focuses on the government policy incentive system and the corresponding financial support incentive mechanism under the government and real estate developers of the two interests of the wisdom of community development strategy evolution and development, and get valuable research conclusions. However, given the relevance and emphases of the evolutionary game analysis method, the model hypothesis can't fully reflect the characteristics of the real estate industry in the development of the smart community, as well as the specific implementation of the smart community development incentive measures, there are some limitations. The next step of the study is based on the selection of specific real estate developers of the smart community, highlighting the real estate industry characteristics of the smart community evolution of the game model to explore more targeted smart community development.

\section{Acknowledgments}

This work is partially supported by National Natural Science Foundation of China No.71372120, Dalian city association of social science No. 2015dlskzd129, Dalian Jinzhou New District Science and Technology Project No. KXYJ-RKX-2015-001. 


\section{References}

[1] H.A. Simon: American Economic Review, 2000, 49(3):253-283.

[2] D. Anrong, G Li and Li J: Irspsd International, Vol.4(2016) No.1, p.78.

[3] V.A. Elia: World Scientific Book Chapters, Vol.2(2016) No.3, p.51.

[4] K. Wu: Hebei Academic Journal, Vol.33(2013) No.5, p.113. (In Chinese)

[5] S.P. Li: Contemporary Finance \& Economics, (2003) No.7, p.76. (In Chinese)

[6] Y. Shen, Y.W. Chai and X.J. Ma: Modern Urban Research, (2003) No.10, p.76. (In Chinese)

[7] F. Lei, L. L.M: Science Technology \& Industry, Vol.149(2011) No.2, p.274.

[8] P. R. Carlos, C. A. Jose: Physics of Life Reviews, Vol.6(2009) No.4, p.208. 